Report No. BMI-1309

UC-25 Metallurgy and Ceramics

(TID-4500, 14th Ed.)

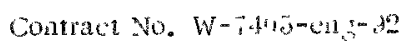

\title{
PREPARATION AND PROPERTIES OF URANIUMA MONOCARBIDE CASTINGS
}

by

Arthur C. Secrest, Jro

Ellis L. Foster

Ronald F. Dickerson

January 2. 1959

BATTELLE MEMORIAL INSTITUTE

505 King Avenue

Columbus 1. Ohio 


\section{DISCLAIMER}

This report was prepared as an account of work sponsored by an agency of the United States Government. Neither the United States Government nor any agency Thereof, nor any of their employees, makes any warranty, express or implied, or assumes any legal liability or responsibility for the accuracy, completeness, or usefulness of any information, apparatus, product, or process disclosed, or represents that its use would not infringe privately owned rights. Reference herein to any specific commercial product, process, or service by trade name, trademark, manufacturer, or otherwise does not necessarily constitute or imply its endorsement, recommendation, or favoring by the United States Government or any agency thereof. The views and opinions of authors expressed herein do not necessarily state or reflect those of the United States Government or any agency thereof. 


\section{DISCLAIMER}

Portions of this document may be illegible in electronic image products. Images are produced from the best available original document. 
ABSTRACT . . . . . . . . . . . . . . . . . . . . . 1

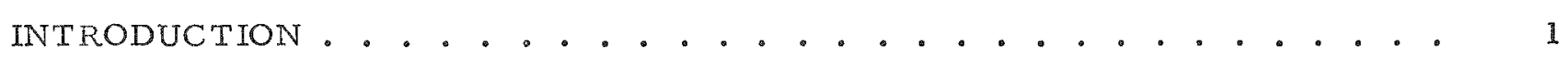

DEVELOPMENT OF MELTING AND CASTING TECHNIQUES FOR UC . . . . . 2

Preparation of UC Melting Stock . . . . . . . . . . . . . 2

Experimental Casting Procedure . . . . . . . . . . . . . 4

Reproducibility of Casting Procedure . . . . . . . . . . . 7

PROPERTIES OF CAST UC . . . . . . . . . . . . . . . . . . 7

Thermal Conductivity . . . . . . . . . . . . . . . 8

Thermal Expansion . . . . . . . . . . . . . . . . 9

Metallography, Heat Treatment, and Mechanical Properties . . . . . 9

The rmal Cycling . . . . . . . . . . . . . . . . . . 11

Observations on the Surface Preparation of Cast UC . . . . . . . . 11

SUMMARY AND CONCLUSIONS .................... . . 13

DISCUSSION . . . . . . . . . . . . . . . . . . . . 14

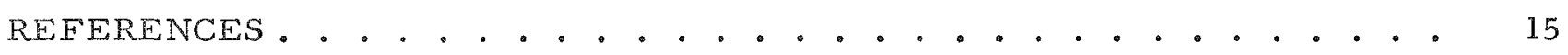




\title{
PREPARATION AND PROPERTIES OF URANIUM MONOCARBIDE CASTINGS
}

\author{
Arthur C. Secrest, Ellis L. Fostex, \\ and Ronald F. Dickerson
}

\begin{abstract}
L sine a special arc-melting technique, sound, homogeneous 1 no-g cylindrical castings of $\mathrm{C} C$ of near stoichiometric composition uere consistently produced. In the casting process developed, LC butions previously prepared by arc melting the elements were placed over the opening of a graphite mold in a helium-atmosphere arc furnace. IThen the l'C button became fully molien under the arc, it dropped by gravity into the mold. The densities of the resultant castings were about 98 per cent of theoretical. The castings could be successfully machine ground using a uater-base cutting fluid.
\end{abstract}

In a preliminary determination of some phicical properties of cast $L C$, the thermal conductivit measured at 100 , 100 , and 500 C was 0.060 .0 .053 , and $0.060 \mathrm{cal}(\mathrm{sec})(\mathrm{cm})(\mathrm{C})$, respectively. The mean linear thermal expansion coefficient in the temperature range from 20 to 950 C was $11.1 \times 10^{-6}$ per C. Cast CC encapsuled in stainless steel exhibited good resistance to thermal stress and shock in two series of tests of 100 thermal cycles to $900 \mathrm{C}$ and 100 cycles to $1100 \mathrm{C}$.

Heat treating a casting specimen for 1 hr at 1000 C produced no significant change in microsiructure, but after a subsequent exposure of $1 \mathrm{hr}$ at 1500 C hardening and the appearance of the $L_{2} C_{3}$ phase were evident. In tests of compressive strength on a single specimen rupture occurred at 51, 500 psi.

\section{INTRODUCTION}

The continuing search for better fuel materials for nuclear reactors is prompted by the economic advantages to be gained from long-life fuel elements and increased fuel temperatures. Atomics International, acting for the Atomic Energy Commission, shares this interest directly in the evaluation of vaxious types of fuels for use in the Sodium Reactor Experiment (SRE), an experimental nuclear power plant located near Los Angeles, California. The research on uranium carbide discussed in this report was performed at Battelle in support of the SRE program.

A number of material properties must be known before the economic potential of a suggested fuel can be evaluated. Some of the more obvious qualities that are desired in a reactor fuel material are high uranium density, good thermal conductivity, and dimensional and physical stability when subjected to in-pile radiation. In addition, the feasibility of fabricating the material in a form suitable for reactor application must be demonstrated.

Several materials now used in reactors possess acceptable qualities under the conditions imposed by the present state of reactor technulogy. Unalloyed uranium, uranium alloys, and uranium dioxide are all being employed singularly or in combinations in power reactors with varying degrees of success. However, in all cases an economic advantage would be gained if the material could be operated at a higher power density (high temperature) and/or for longer periods of time between replacement. 
A material that offers considerable promise to fulfill these requirements as a reactor fuel is uranium monocarbide. In addition to its high uranium density, it has a thermal conductivity near that of uranium, it is refractory. and it has a structure (facecentered cubic) that is theoretically capable of considerable resistance to radiation damage. Furthermore, in spite of its high melting point, it appears that uranium monocarbide can be fabricated directly to fuel elements by casting techniques. Although uranium monocarbide has received some attention by reactor technologists from time to time, very limited irradiation data are available. Likewise. no information is available in the literature ith regard to casting of special shapes, such as would be required for use as reactor fuel elements. However, uranium carbide can be prepared by arcmelting elemental uranium and carbon $(1,2,3,4)$.

Because of its promise as a fuel material, a study with the objectives of developing casting techniques and determining some of the physical properties of cast UC was initiated. The ultimate aim was to produce cast shapes of uranium monocarbide of near stoichiometric composition ( $4.8 \mathrm{w} / \mathrm{o}$ carbon) in a predictable and reproducible manner. Most of the research was done on carbide of about $5.0 \mathrm{w} / 0$ carbon.

\section{DEVELOPMENT OF MELTING AND CASTING TECHNIQUES EOR UC}

\section{Preparation of UC Melting Stock}

Based on past experience, a modified arc-melting process was believed to be the best method for preparing high-quality UC. An advantage of the arc-melting technique is that the extremely high temperatures required for melting uranium monocarbide can be reached and maintained with good control. Previous work had shown that a tungstentip electrode seriously contaminated UC melts. Therefore, a nonconsumable, carbontip electrode was chosen since the only contaminant from such an electrode would be carbon.

Buttons were made by arc melting freshly pickled center-cut biscuit uranium (1'2-in. squares, 50 to 90 mils thick) with crushed spectrographic carbon (1/4 by 5'8in. pieces) in a water-cooled copper crucible under a helium atmosphere of 10 to $20 \mathrm{in}$. of mercury. The arc was struck initially on a piece of uranium at $200 \mathrm{amp}$ and 30 to $32 \mathrm{v}$. then raised to 500 amp to obtain a molten pool. It was found that carbon pickup from the electrode tip was minimized if the melting time was held to $30 \mathrm{sec}$ per melt and if the carbon tip was rounded rather than pointed. A procedure involving a total of six romelts per button for $30-\mathrm{sec}$ intervals produced consistently homogeneous buttons. A specially designed furnace (see Figure 1) was used whereby the button could be flipped over after each melt without opening the furnace.

(1) References at cnd. 


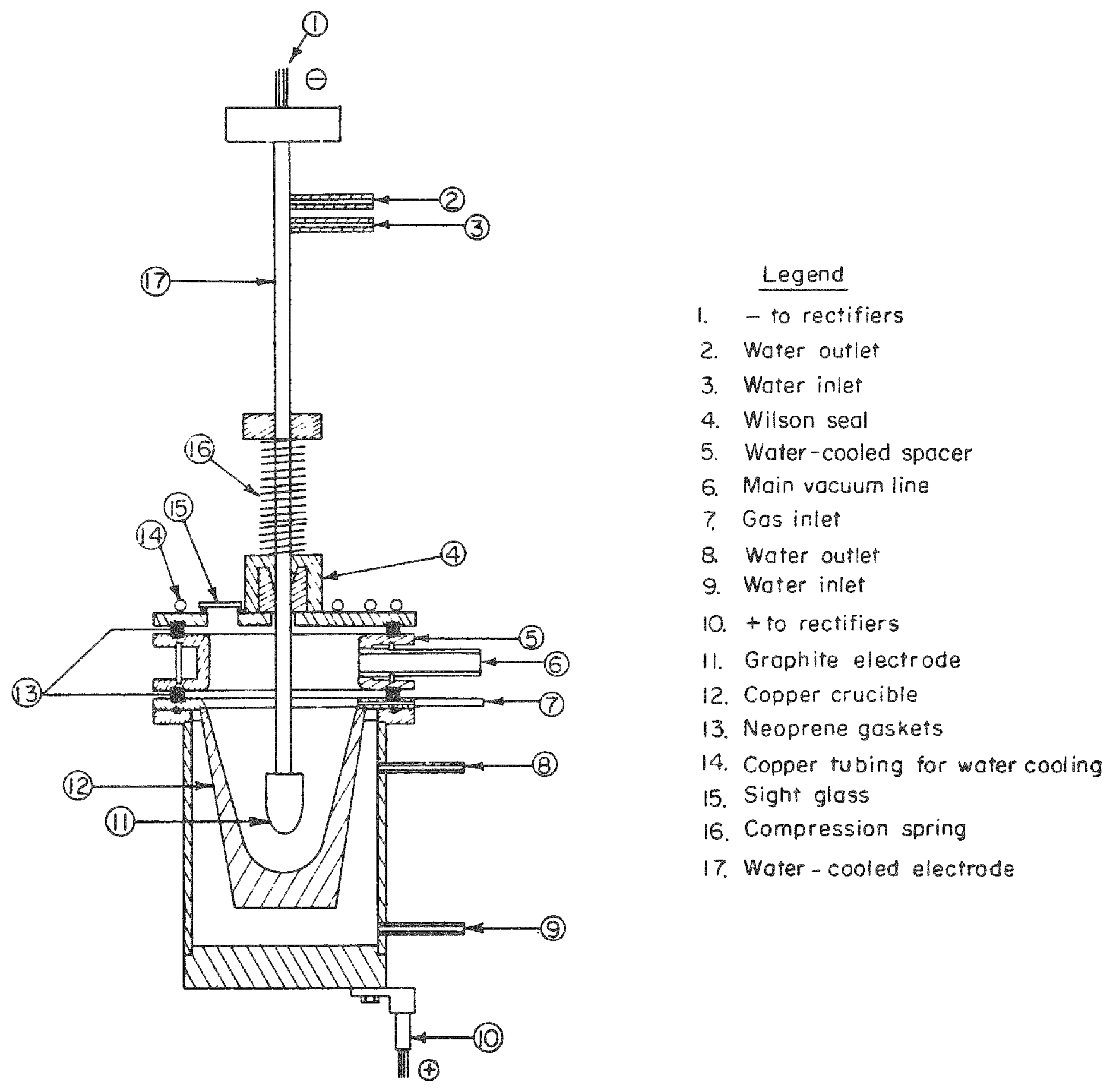

FIGURE 1. CHARGE-FLIPPING ARC FURNACE 
Experimental Casting Procedure

Preliminary investigations showed that casting of UC was a feasible process but that certain refinements and modifications of conventional axc-melting techniques were required in order to obtain sound specimens. For example, it was demonstrated that both in a copper mold and in a solid graphite mold the casting cracked as a result of cooling too rapidly. On the other hand, a graphite thimble mold proved to be quite satisfactory: cooling was slow enough to prevent cracking and no attack of the mold was noted. Usually, the castings slipped out of the thimble easily, thus allowing the mold to be used several times.

Using this type of thin-walled graphite mold, a "drop-casting" technique was adopted for producing cast specimens $3 / 8$ in. in diameter by $1-3 / 4$ in. long. As shown in Figure 2, the mold was suspended in the cavity of a copper supporting block by an integral graphite collar inside an arc-melting furnace. The component parts together with the assembled mold, button, and a finished casting are shown in Figures 3 and 4. In the technique used, a 100-g arc-melted button of UC was placed on the collar of the mold and most of the button was melted by passing a low-amperage arc in concentric circles over the surface of the button. This operation also served to preheat the mold. By increasing the current and power supplied to the arc and by holding the arc directly over the mold opening, all of the UC button was caused to melt and to suddenly drop into the mold as one mass. The steps involved in the casting procedure were as follows:

(1) Evacuate arc-melting furnace

(2) Introduce helium to approximately $20 \mathrm{in.}$ of mercury

(3) Strike off arc on button using 200 amp at 30 to $32 \mathrm{v}$

(4) Increase to 400 to $600 \mathrm{amp}$ to obtain round molten pool and preheat mold (time: about $60 \mathrm{sec}$ )

(5) Increase to $800 \mathrm{amp}$ and hold until molten UC drops (time: 15 to $30 \mathrm{sec})$

(6) Shut off power to arc and evacuate chamber until red glow has disappeared (time: 1 to $2 \mathrm{~min}$; a significant reduction in the cooling rate was achieved by this evacuation procedure)

(7) Bleed in helium to approximately 20 in. of mercury (to speed cooling by conduction after black heat is obtained)

(8) Remove casting after about 10 min.

Small castings prepared by the above procedure were extemely well formed and free of cracks. This success was attributed in part to the fact that a 1/32-in. hole was drilled through the bottom of the mold to allow entrapped gases to escape. Surfaces were smooth and in general had a metallic appearance. Density measurements on a typical casting produced an average value of $13.4 \mathrm{~g}$ per $\mathrm{cm}^{3}$, or 98 per cent of the theoretical value of UC. In general, no porosity was observed in the microstructures. 


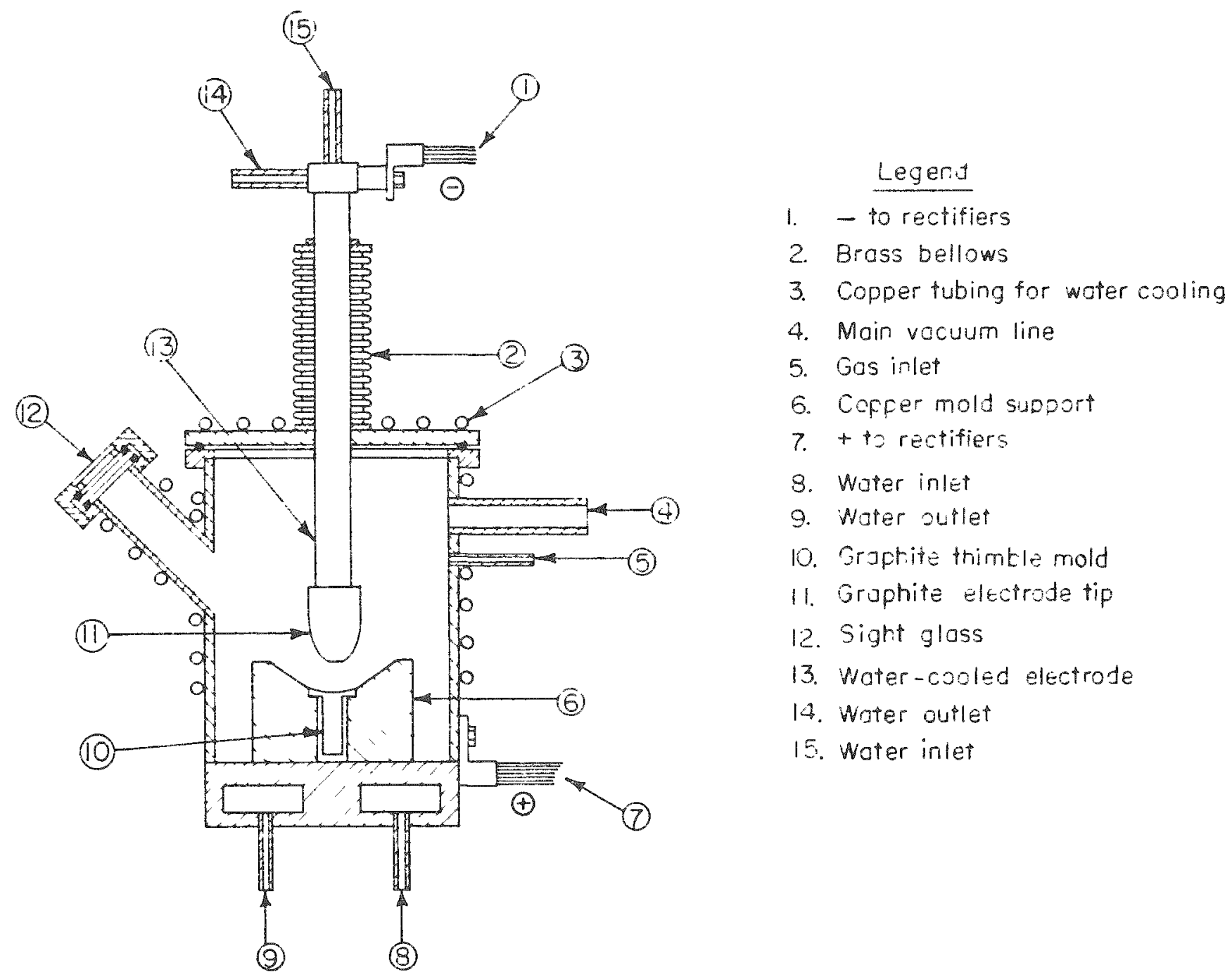

FIGURE 2. LABORATORY-TYPE ARC FURNACE WITH GRAPHITE THIMBLE MOLD AND COPPER MOLD SUPPORT 

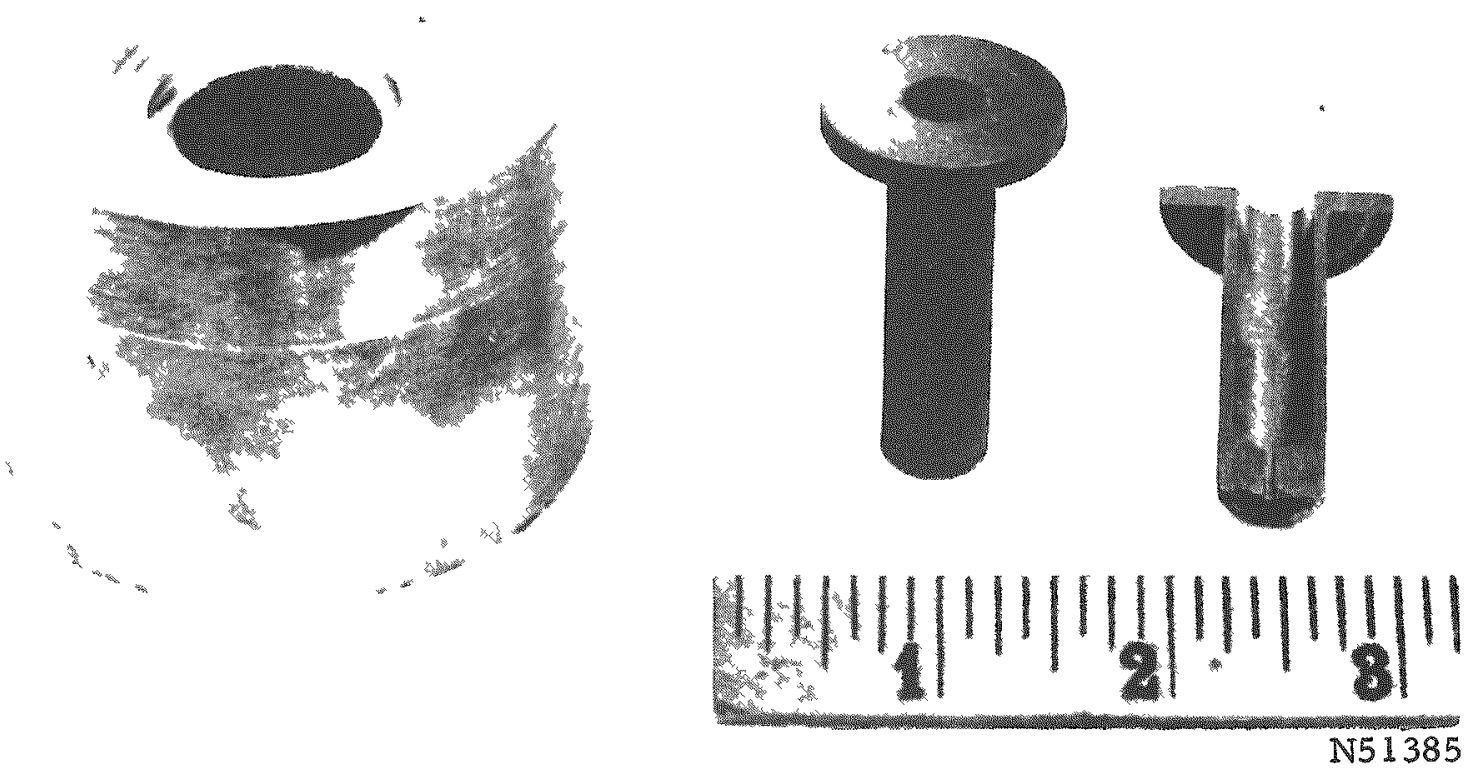

FIGURE 3. COPPER SUPPORT AND GRAPHITE THIMBLE MOLD FOR MAISING UC CASTINGS

Notice hole for degassing in bottom of mold sectioned.
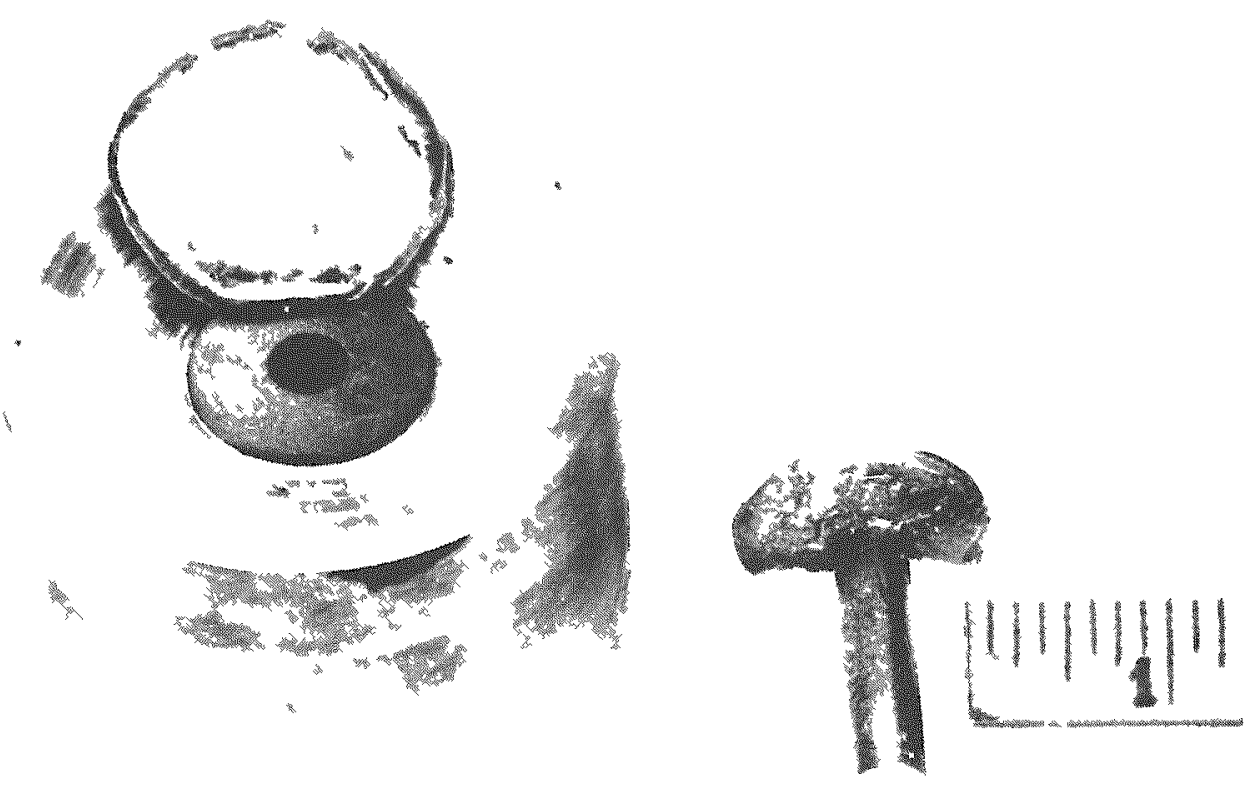

N51387

FIGURE 4. ASSEMBLED MOLD WITH ARC-MELTED UC BUTTON CHARGE AND FINISHED CASTING 
While sound castings of UC about $3 / 8 \mathrm{in}$. in diameter by $1-3 / 4 \mathrm{in}$. long could be produced readily by the drop-casting method, the preparation of larger specimens was found to be increasingly more difficult as the size increased. Imperfections such as shrink cavities, cracks, or surface roughness were present in larger castings.

Early in the program it was recognized that a more promising casting procedure for economical production of UC fuel-element shapes would involve skull-type arcmelting techniques. With this type of casting technique, a number of the shapes could potentially be cast at one time, composition control in terms of carbon content would be improved, and the molds could be more readily adapted to give the necessary mold temperatures and casting cooling rates. However, the size, shape, and number of specimens required for the physical tests of this research program did not justify the developmental efforts that would have been required. Attempts to prepare a large skull casting using $200-\mathrm{g}$ UC charges in a bench-scale tilting-hearth arc furnace were unsuccessful only because the cast shapes, while well formed, cracked on cooling. The cracking was attributed to the use of an unheated copper mold and to the inherent rapid cooling of the casting in such a mold. If the copper mold had been replaced by a heated. graphite thimble mold the cracking undoubtedly would have been prevented, as demonstrated by the drop-casting procedure.

\section{Reproducibility of Casting Procedure}

While the UC button is molten, it is subject to carbon pickup from both the graphite thimble mold and the carbon-tip electrode. The finished casting is, therefore, subject to possible variations in carbon content. In order to determine the reproducibility of composition of specimens prepared by a standard melting and casting procedure, four castings were made from eight $100-\mathrm{g}$ buttons. These buttons, each having been melted six times to achieve homogeneity, varied by only $0.1 \mathrm{w} / 0$ from the desired $4.8 \mathrm{w} / 0$ carbon content. The castings also showed excellent reproducibility and good uniformity in composition from top to bottom. All sections from the top, middle, and bottom portions had carbon contents of $4.9 \mathrm{w} / 0 \pm 0.1 \mathrm{w} / \mathrm{o}$. These analytical results were substantiated by metallographic examination. It has thus been established that the arc-melting procedure can be adequately controlled to yield buttons and castings of consistent composition.

\section{PROPERTIES OF CAST UC}

To evaluate the applicability of uranium monocarbide as a reactor fuel material, several properties and characteristics of the material must be known. Properties of the cast monocarbide would, in general, be expected to be similar to those of the carbide prepared by other techniques. However, the cast material may be expected to exhibit some superiority with regard to density, purity, and handling characteristics because there is less opportunity for contamination during its preparation. Some of the physical properties of UC presently available from the literature are listed in Table 1. 
TABLE 1. PHYSICAL PROPERTIES OF URANIUM MONOCARBIDE $(1,3,4,5)$

\begin{tabular}{lc}
\hline \hline Surface appearance & Metallic luster \\
Theoretical density & $13.63 \mathrm{~g} \mathrm{per} \mathrm{cm}^{3}$ \\
Melting point & $2350 \mathrm{C}$ \\
Crystal structure & Face-centered cubic, \\
& $a=4.951 \mathrm{~A}$ \\
Stability & Decomposed by water \\
\hline
\end{tabular}

To supplement these data, studies were conducted on cast UC to obtain information on thermal conductivity and thermal expansion. Additional information was gained from metallographic, heat-treatment, thermal-cycling, and surface-preparation studies.

\section{Thermal Conductivity}

A casting larger than those prepared for the compositional reproducibility study was desired for the thermal-conductivity measurement. A specimen $1 / 2$ in. in diameter by $2 \mathrm{in.} \mathrm{Iong,} \mathrm{having} \mathrm{a} \mathrm{composition} \mathrm{of} 5.2 \mathrm{w} / \mathrm{o}$ carbon, was successfully prepared by the drop-casting technique. Values for steady-state conditions over the temperature range from 100 to $735 \mathrm{C}$ are given in Table 2. While the thermal conductivity of $\mathrm{UO}_{2}$ decreases with increasing temperature over this range, this sample of $U C$ reached a minimum at about $400 \mathrm{C}$ and at $700 \mathrm{C}$ was equal to the initial value. These values were obtained on a single specimen and additional tests will be required to determine whether the values are generally characteristic of UC.

TABLE 2. THERMAL CONDUCTIVITY OF URANIUM MONOCARBIDE

\begin{tabular}{cc}
\hline Temperature, C & $\begin{array}{c}\text { Thermal Conductivity, } \\
\text { cal/(sec) }(\mathrm{cm})(\mathrm{C})\end{array}$ \\
\hline 100 & 0.060 \\
150 & 0.058 \\
200 & 0.056 \\
250 & 0.055 \\
300 & 0.054 \\
450 & 0.053 \\
450 & 0.053 \\
500 & 0.053 \\
550 & 0.054 \\
600 & 0.055 \\
700 & 0.057 \\
735 & 0.058 \\
\hline
\end{tabular}




\section{Thermal Expansion}

The the rmal-expansion coefficients of as-cast machine-ground uranium monocarbide were found to be similar to values reported for $\mathrm{UO}_{2}{ }^{(5)}$ The mean linear thermalexpansion coefficients determined and calculated for temperature ranges from 20 to $950 \mathrm{C}$ are presented in Table 3 , and the experimental dilation data are plotted in Figure 5.

TABLE 3. MEAN LINEAR THERMAL-EXPANSION COEFFICIENTS OF CAST UC

\begin{tabular}{|c|c|c|}
\hline \multirow{2}{*}{$\begin{array}{l}\text { Temperature } \\
\text { Range, } C\end{array}$} & \multicolumn{2}{|c|}{$\begin{array}{l}\text { Thermal Expansion on First Thermal Cycle, } \\
10^{-6} \text { per } \mathrm{C}\end{array}$} \\
\hline & Heating & Cooling \\
\hline $20-100$ & 9.5 & 10.3 \\
\hline $100-200$ & 10.1 & 10.6 \\
\hline $200-300$ & 10.7 & 11.1 \\
\hline $300-400$ & 11.1 & 11.7 \\
\hline $400-500$ & 11.4 & 12.2 \\
\hline $500-600$ & 11.6 & 12.4 \\
\hline $600-700$ & 12.1 & 12.8 \\
\hline $700-800$ & 12.2 & 13.1 \\
\hline $800-900$ & 12.6 & 13.4 \\
\hline $900-950$ & 13.0 & 13.6 \\
\hline
\end{tabular}

Metallography, Heat Treatment, and Mechanical Properties

The method for preparing UC specimens for microscopic examination consisted of mounting in Bakelite, grinding through 600-grit SiC papers with kerosene as a lubricant, and polishing first on a wheel covered with Forstmann's cloth impregnated with diamond paste and finally on Microcloth impregnated with Linde " $B$ " alumina abrasive suspended in water. The final polishing time was kept short so that the contact with water was brief. The polished specimens were then etched by immersion in an etchant consisting of equal volumes of nitric acid, acetic acid, and water. An etching time of 5 to 20 sec was usually adequate.

The monocarbide is one of three carbides in the uranium-carbon system; the other two are the sesquicarbide $\left(\mathrm{U}_{2} \mathrm{C}_{3}\right)$ and the dicarbide $\left(\mathrm{UC}_{2}\right)$.

Figures 6 and 7 show the differences between the microstructures of arc-cast UC containing the $4.8 \mathrm{w} / \mathrm{o}$ carbon and alloys containing $4.5 \mathrm{w} / 0$ and $5.0 \mathrm{w} / \mathrm{o}$ carbon. The alloy containing only $4.5 \mathrm{w} / 0$ carbon contains appreciable amounts of alpha uranium as a white phase at the grain boundaries and as isolated small globules. The matrix is the UC phase. The second phase in the higher-than-stoichiometric composition is $\mathrm{UC}_{2}$, which appears as a light phase at the grain boundaries and also in the Widmanstätten pattern within each grain. Again, the matrix is the UC phase. 


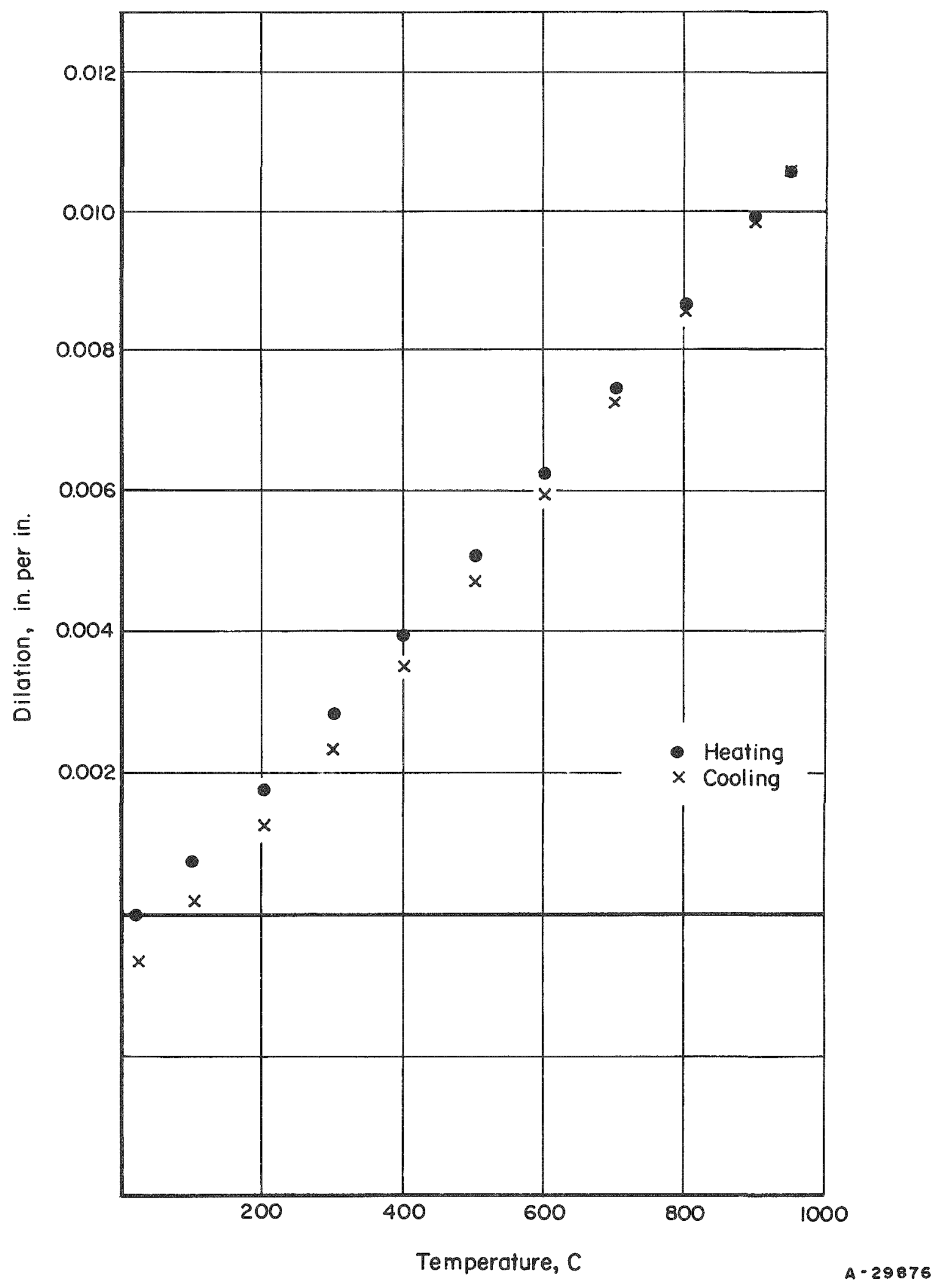

FIGURE 5. DILATION VERSUS TEMPERATURE FOR AS-CAST URANIUM CARBIDE 
Heat treating a specimen containing $5.2 \mathrm{w} / 0$ carbon at $1000 \mathrm{C}$ for $1 \mathrm{hr}$ produced no significant change in microstructure, whereas further heating to $1500 \mathrm{C}$ for $1 \mathrm{hr}$ was accompanied by a broadening of the precipitated phase as shown in Figure 8. Similar heat treatments and change in microstructure have been associated in the past with the appearance of the sesquicarbide or $\mathrm{U}_{2} \mathrm{C}_{3}$ phase. (1)

An apparent increase of about 200 Vickers hardness resulted from the $1500 \mathrm{C}$ heat treatment (Figure 8b). However, these hardness measurements should not be regarded as too meaningful because the treated and untreated materials differed in fracture sensitivity to the hardness indenter. This difference in hardness and fracture behavior perhaps indicates that heat treatment of the inonocarbide may produce some stressrelieving or other toughening effect.

A single test of the compressive strength of a cast UC specimen was also made. A sample $3 / 8 \mathrm{in}$. in diameter by 1-5/8 in. long was subjectrod to three loading cycles at stresses up to $5,450,27,250$, and 54,500 psi. Rupture occurred at 54,500 psi. The average value of the modulus of elasticity from the three cycles was $31.5 \times 10^{6}$ psi. The strain was elastic over the stress ranges until rupture. Up to this stress, a total strain of 0.17 per cent was observed.

\section{The rmal Cycling}

UC specimens in the as-cast and machine-ground condition with carbon contents ranging from 4.5 to $5.0 \mathrm{w}$ / 0 carbon were subjected to two series of thermal-cycling tests. The first test was 100 thermal cycles to $900 \mathrm{C}$ and the second test was 100 thermal cycles to $1100 \mathrm{C}$. All specimens were still intact after testing and exhibited no evidence of cracking or growth. Each therinal cycle comprised heating at the specified temperature for $15 \mathrm{~min}$ in an evacuated quartz tube, followed by a 15 -min cooling period at room temperature. During the tests at $900 \mathrm{C}$ and $1100 \mathrm{C}$ specimens of the three different compositions were in contact with Type 304 stainless steel. No attack on the stainless was noted.

Observations on the Surface Preparation of Cast UC

Due to the tendency of all uranium carbides to react with water, contact of UC specinens with water or water vapor was avoided, whenever possible. Consequently, all buttons and castings were stored in desiccators to provide adequate protection.

For certain physical-property determinations on UC it was necessary to have cylinders of uniform diameter. Machine grinding was found to work satisfactorily. Specimens ground on an Alundum wheel, using a water-base cutting fluid, showed no fracturing. but some loading of the wheel, accompanicd by spalling of the specimen, was uncountered. Substitution of a resin-bonded diamond wheel for the Alundum wheel completely eliminated the spalling tendency. During the grinding operation, the specimen was held between pressure pads and moved back and forth against the edge of the grinding wheel. Some specimens were ground to as small as $1 / 1 \mathrm{in}$. in diameter by 1 in. long. In spite of the tendency of UC to react with water, no detrimental effects were observed on the ground specimens as a result of using a water-base cutting fluid. 


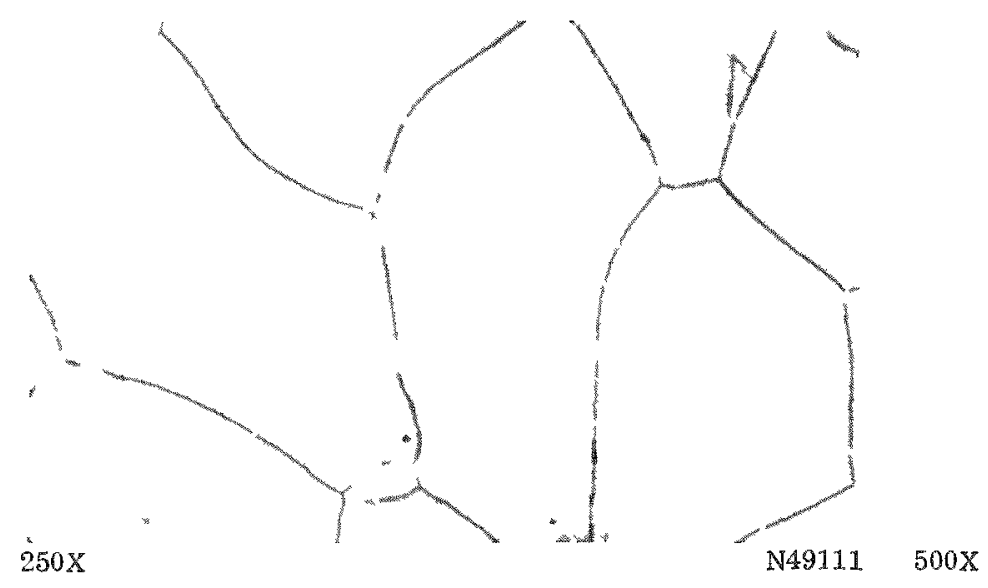

a. Uranıum-4.8 w/o Carbon

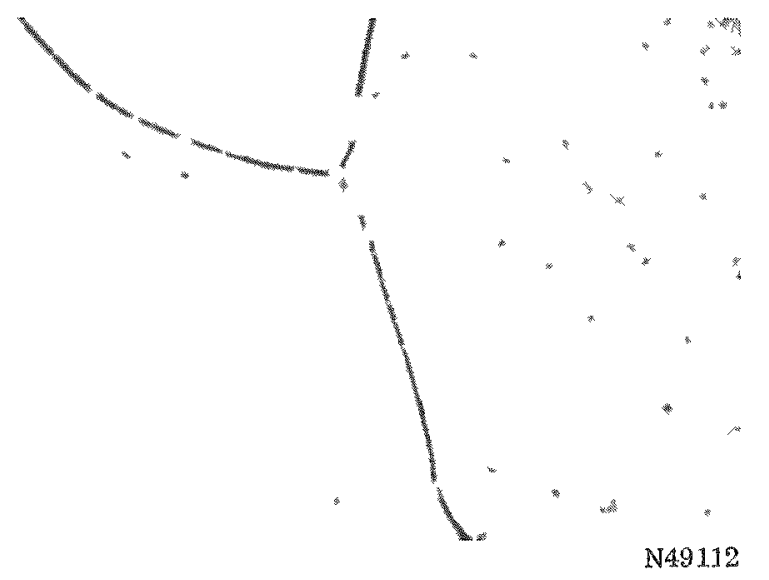

b. Uranumm $-4.8 \mathrm{w} / 0$ Carbon

FIGURE 6. CAST STRUCTURE OF URANIUM MONOCARBIDE

A trace of excess metallic uranum appears as white patıcles.

$250 \mathrm{x}$

a. Uranium -4.5 w/o Carbon

Uranum (White) plus uranium carbide

RM10908 250X

\section{FIGURE 7. CAST STRUCTURE OF URANIUM-CARBON ALLOYS}

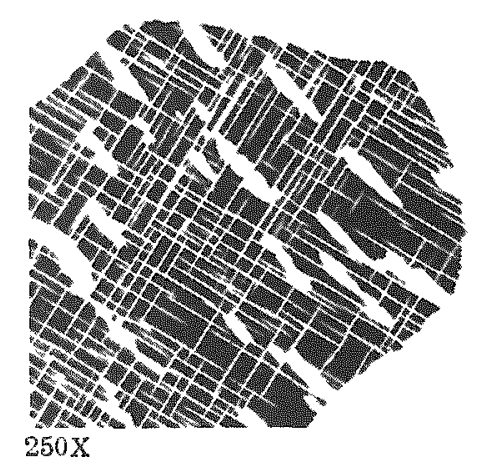

a. After $1 \mathrm{Hr}$ at $1000 \mathrm{C}$ in Vacuum UC plus UC2; 560 DPII

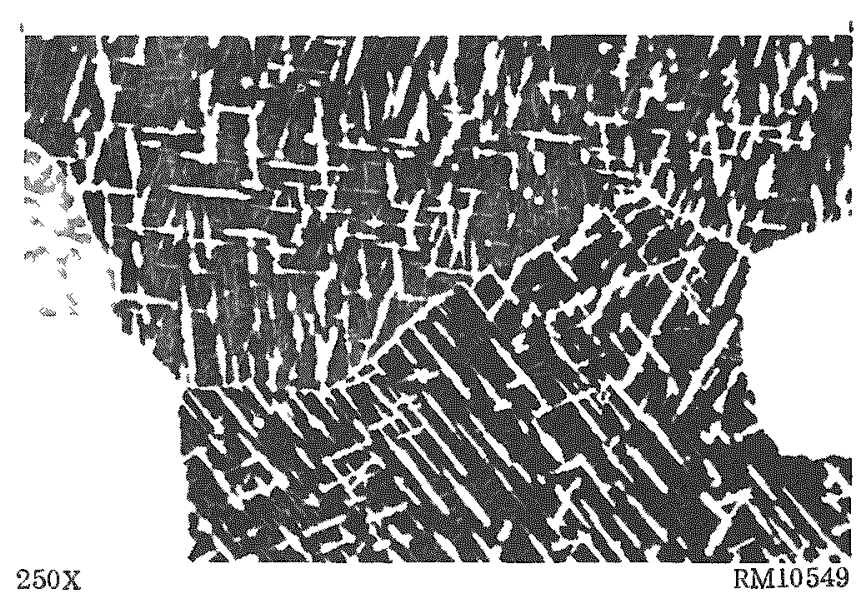

b. After 1 Hr at $1500 \mathrm{C}$ an Vacuum UC plus $\mathrm{U}_{2} \mathrm{C}_{3} ; 760 \mathrm{DPH}$

FIGURE 8. EFEECTS OF HEAT TREATING CAST URANIUM-5.2 W/O CARBON 
However, immediately after grinding the specimens were wiped dry and stored in a desiccator.

All machine-ground specinens were radiographed using a cesium-137 source to determine the soundness of specimens. If any defects were present they were revealed in the two exposures taken with the specimens rotated 90 deg. The sensitivity of the examination was sufficient to reveal occasional tiny threadlike defects.

It was observed that machine-ground cast specimens tended to fracture on standing in air more rapidly than did unground castings. On the basis of $X-r a y$ and carbon analyses, this difference in stability was attributed to the presence of a thin surface layer of $\mathrm{UC}_{2}$ on the as-cast unground material. The higher concentration of carbon resulted from contact of the molten monocarbide with the graphite mold. This observation is in agreement with the reported higher stability of $\mathrm{UC}_{2}$ in air at room temperature. $(3,4)$

\section{SUMMARY AND CONCLUSIONS}

The technique for producing sound, honıgeneous castings of uranium monocarbide involving the preparation of arc-melted material by direct alloying of the elements and subsequent arc melting and casting in graphite thimble molds appeared successful. Castings produced by this method were satisfactorily machine ground using a water-base cutting fluid with no evidence of fracturing or other detrimental effects.

Excellent compositional reproducibility and homogeneity were achieved in the preparation of arc-melted UC buttons and castings by adopting a uniform melting and casting procedure. These compositional data were obtained on small buttons and on 3/8-in.-diameter by $1-3 / 4$-in.-1ong castings containing approximately $4.8 \mathrm{w} / 0$ carbon.

In the preliminary study of the physical properties of UC it was found that the thermal conductivity of this material, unlike that of $\mathrm{UO}_{2}$ which decreases with increases in temperature over the range from 100 to $700 \mathrm{C}$, decreased only to $400 \mathrm{C}$ and then increased with temperature. The value measured at $700 \mathrm{C}, 0.060 \mathrm{cal} /(\mathrm{sec})(\mathrm{cm})(\mathrm{C})$, was identical with that obtained at $100 \mathrm{C}$.

In thermal-cycling tests made on encapsulated cast uranium monocarbide samples containing 4.5 to $5.0 \mathrm{w} / 0$ carbon at both 900 and $1100 \mathrm{C}$, no evidence of fracturing or growth was observed after 100 thermal cycles $15 \mathrm{~min}$ in a furnace at temperature followed by a $15-\mathrm{min}$ cooling period in room-temperature air).

Based on density, thermal-conductivity, and thermal-cycling data, cast uranium monocarbide appears to have all the necessary requirements for use as a reactor fuel material. However, other factors, such as its resistance to irradiation danage and its compatibility with materials used in reactors, need to be studied. On the basis of the preliminary studies reported here, there is every reason to believe that it will be feasible to prepare uranium monocarbide by casting techniques for use as a reactor fuel. 


\section{DISCUSSION}

In general, cast UC has been shown to exhibit properties that make its use as a fuel exceptionally attractive for certain reactors. However, if it is to find useful application many additional studies should be conducted. These studies should include inquiries into the variation in physical and mechanical properties caused by small changes in impurity or carbon content. Concurrent with these studies of properties two specific fields suggest themselves as areas of profitable inquiry. These relate more directly to the fabrication of cast UC as a fuel element.

The drop-casting technique developed in the course of this work proved satisfactory for the preparation of small experimental castings. However, any large-scale production of cast UC fuel elements will necessitate a more practical and economical casting method. A promising method for production casting was briefly touched upon in this investigation. It involved using a skull-type arc-melting furnace in which the melting and casting operations are carried out consecutively. This method has several potential advantages that cannot be found in any other preparation procedure:

(1) A number of fuel elements could be cast at one time and the molding could be devised to give any desired mold temperature and cooling rate for the casting.

(2) Since arc-melting cycles are very short, high production rates could be achieved with a minimum number of furnaces.

(3) The furnaces, with the exception of the associated handling and molding equipment, also could be used in other metallurgical melting operations.

Developmental studies are needed in ordex to scale up the current laboratory process for the production of fuel slugs by this skull-arc-melting technique.

The highly reactive chemical nature of UC suggests a field for additional studies on the oxidation resistance and protection of this material. It was observed during the course of this study that a thin coating of $\mathrm{UC}_{2}$ is beneficial to the room-temperature stability of cast UC fuel elements. Evidently, this film is formed when the molten UC is cast into graphite molds. While very thin, its presence has been confirmed by X-ray diffraction. The protection was evidenced by the ability of unmachined cylindrical surfaces of cast specimens exposed to the atmosphere to remain intact even though some corrosion and cracking was always noted on the cut end. If it is contemplated to use large numbers of cast shapes as fuel elements, the inspection and handling of the elements would be greatly simplified by the presence of a resistant coating, such as $\mathrm{UC}_{2}$. One of a number of possible methods for applying such a coating might be a gas carburization process to change the surface film from UC to high-integrity $U_{2}$. This film would serve not only to protect the entire specimen from surface deterioration but would also minimize the effect of small irregularities on the surface of the cast specimens. This coating would thereby reduce the tendency of atmospheric corrosion to open cracks. 


\section{REFERENCES}

(1) Mallett, M.W., Gerds, A. F., Nelson, H. R. "The Uraniun-Carbon Systen", J. of Electrochem. Soc., 99, 197-204 (1952).

(2) "Development and Preparation of Uranium Monocarbide Cermets", report prepared by Armour Research Foundation under Subcontract No. 73-(14-412), Prime Contract No. Al-11-gen-14) (September 17, 1956). Confidential.

(3) Gray, R. J.. Thurber, W. C., DuBose, C. K. H., "Preparation and Metallography of Arc-Melted Uranium Carbides", ORNL-2446 (1958).

(4) Gray, R. J.. Thurber, W. C., DuBose. C. K. H., "Preparation of Arc Melted Uranium Carbides", Metal Progress, 74 (1), 65 (July, 1958).

(5) Nichols, R. W., "Curamic Fuels. Properties and Technology", Nuclear Engineering, $3.327-333(1958)$.

ACS/ELF/RFD:pa 